\title{
THE SURGICAL TREATMENT OF PORTAL HYPERTENSION
}

\author{
By A. G. RIDDELl, M.B.E., M.S., F.R.C.S. \\ Senior Lecturer in Surgery, University of Manchester
}

It is just over ro years since Whipple (1945), in his now classic paper, gave the impetus to the surgical treatment of portal hypertension, and this has greatly increased understanding of the disease. It is believed that a short review of the present position would be of value at this time. The paper consists of two main parts, firstly, a review of the current views of the disordered physiology associated with portal hypertension and, secondly, an attempt to outline a plan of treatment. Recent review articles of special interest are those of Child (1955) and Ravdin (1957).

The normal portal pressure is approximately $15 \mathrm{~cm}$. of saline. It is difficult to measure accurately because of the difficulty in defining a suitable reference point, the most usual one taken is the anterior surface of the second lumbar vertebra. The portal pressure may be measured in three ways; ( $\mathrm{I}$ ) direct measurement at operation, (2) percutaneous splenic puncture, and (3) hepatic vein wedge pressure. The first of these methods gives the most reliable recording, the other two give a figure that is slightly lower than that obtained by the direct method. Percutaneous splenic puncture is more generally useful than the measurement of the hepatic vein wedge pressure, as it will give a true reading in the presence of portal vein thrombosis and may also be combined with a splenic portagram. The portal pressure may fall considerably when arterial hypotension occurs at operation.

Portal hypertension has been defined as a pressure in the portal vein or its main tributaries of more than $30 \mathrm{~cm}$. of saline (Child, 1954). In a series of $5^{6}$ patients studied by Child (1955) at operation, the portal pressure varied between 50 and $25 \mathrm{~cm}$. of saline; he further demonstrated that if the portal pressure was reduced, by means of a satisfactory shunt operation, to below $30 \mathrm{~cm}$., haemorrhage from oesophageal varices did not recur. Taylor (1954), however, has shown that in

Based on a paper read to the Section of Surgery, Manchester Medical Society, February 12, 1957
Table 1.-Classification of Portal Obstruction

Intrahepatic $\quad \ldots \quad \ldots \quad \quad \ldots \quad 70$ per cent. of cases Cirrhosis

Hepatic vein thrombosis

Extrahepatic . $\quad \ldots \quad$. 30 , , , , , Portal vein thrombosis

Combined Intrahepatic and Extrahepatic

Cirrhosis with portal vein thrombosis

normal people the portal pressure may rise as high as $50 \mathrm{~cm}$., if the patient strains. The main causes of portal hypertension are shown in Table $\mathrm{I}$.

The mechanism of portal hypertension iso obscure. Only about 30 per cent. of patients with cirrhosis develop portal hypertension, and thereo is no very clear correlation between the portal: pressure and the histological appearance of the liver. It has been suggested that in cirrhosis there are three mechanisms which lead to this rise in pressure; (I) obstruction to portal vein radicles by fibrous tissue, (2) pressure on the portal vein radicles by nodules of regenerating liver tissue, and (3) the presence of arterio-venous shunts within the liver. The mechanical factors are certainly the most important. Whether an individual patient develops portal hypertension or not, probably depends on whether the collateral circulation is adequate to relieve portal congestion. While ligation of the portal vein in the common laboratory animals is uniformly fatal, in monkey and in man ligation of the portal vein is nearly always followed by survival (Child, Milnes, Holswade and Gore, 1950; Child, Holswade, McClure, Gore and O'Neill, 1952). Following this procedure, either in the monkey or in man, portal hypertension does not develop, oesophageal varices do not occur, and ascites does not appear. That ligation of the portal vein is not followed by portal hypertension would, at first sight, make it difficult to understand the mechanism of portal hypertension in patients with an extrahepatic block. Probably, in these patients, there is not only occlusion of the portal vein, but also of some 
of its major tributaries, in such a way that the formation of an adequate collateral circulation is prevented and portal hypertension results. These findings indicate why it has been so difficult to produce oesophageal varices in the experimental animal. Following ligation of the portal vein in the monkey or in the dog, as a staged procedure, perioesophageal collateral veins will develop but oesophageal varices do not. However, oesophageal varices have been produced in the dog in association with cirrhosis of the liver. It is almost certain that oesophageal varices are not, in fact, true collateral channels, but rather that they are the result of distension of the numerous veins of the oesophagus and cardia resulting from portal hypertension.

The two important clinical effects of portal hypertension are the haemorrhage from the oesophageal varices and hypersplenism resulting from congestive splenomegaly. No convincing evidence has been forthcoming to show that ascites will occur in patients with an extrahepatic block and without evidence of liver disease. 'It can be stated, therefore, that ascites does not result directly from a raised portal pressure. The mechanism of ascites is extremely complicated and portal hypertension plays only a minor role in its production. In experimental animals, portal vein ligation will not produce ascites, but it occurs after partial ligation of the inferior vena cava above the diaphragm. This mechanically produced ascites in the experimental animal has its clinical counterpart in man in the Budd-Chiari syndrome. It has been suggested that ascites in association with cirrhosis may sometimes be due to severe reduction in the outflow tract of the liver (Madden, Loré, Gerold and Ravid, 1954). In the average patient with cirrhosis, the presence of ascites indicates that there is severe liver-cell damage. The principal causes of ascites in association with liver disease are given in Table 2. Contrary to popular belief, the incidence of haemorrhoids is not greater in patients with portal hypertension than in the rest of the population, nor, if haemorrhoids develop, are they more likely to bleed than in otherwise normal persons. Another problem of portal hypertension is the lack of understanding of the precise mechanism which causes oesophageal varices to bleed. It has been known for a long time that injection of oesophageal varices is not followed by haemorrhage; Allison (I95I) has stuck relatively large needles into varices to measure portal pressure, and this is not followed by severe haemorrhage. At least one group of workers subscribe to the view that varices disturb the normal mechanism of the cardia and allow reflux of gastric contents, and this is followed by peptic ulceration of the varices which leads to haemorrhage (Wagenknecht, Noble
Table 2.-The Mechanism of Ascites

Low plasma osmotic pressure due to deficient albumen synthesis.

Faulty metabolism of hormones leads to water and salt retention.

Increased lymph production by the liver.

Increased portal venous pressure.

and Baronofsky, 1953). At autopsy, in those patients who have died from haemorrhage and in whom the bleeding point can be identified, it is common to see a shallow ulcer around the opening into the vein.

Disorders of ammonia metabolism have come into prominence in patients with liver disease and portal hypertension in recent years (McDermott, Riddell and Adams, 1954; Riddell, I955a and b). Ammonia intoxication has been shown to be an important cause of death in patients immediately following severe haemorrhage from oesophageal varices (McDermott, Wareham and Riddell, 1956), see Fig. r. Blood within the lumen of the alimentary tract is broken down, by bacterial action, to form ammonia; this is absorbed into the portal system, and in patients with portal hypertension, passes along the collaterals rather than through the liver and is, therefore, not immediately detoxicated in the liver; as a result, ammonia intoxication occurs.

Although a much clearer picture can be obtained of the pathological aspects of this disease than was

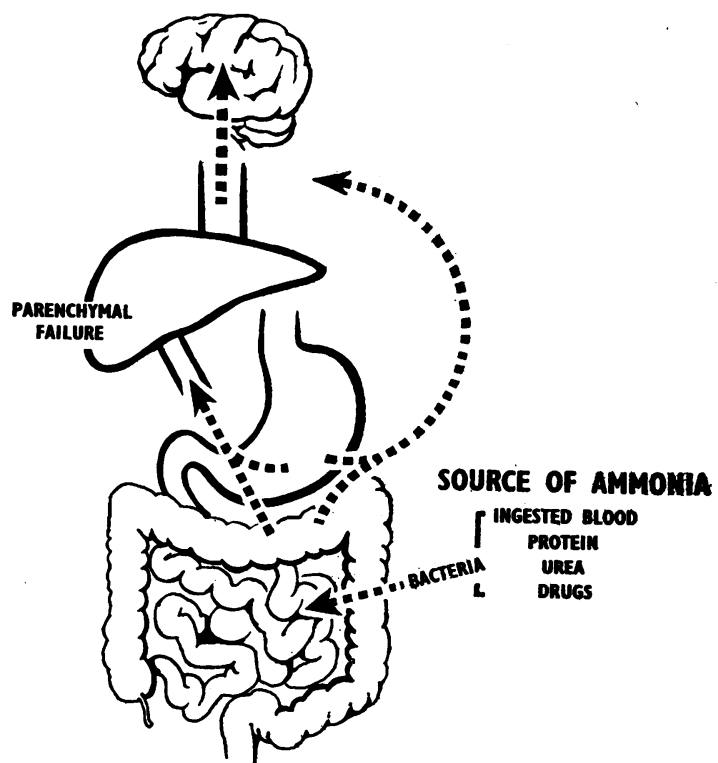

FIG. 1.-The mechanism of ammonia intoxication. In patients with portal hypertension, ammonia formed in the gut may pass around the liver, by way of collateral channels, to produce portasystemic encephalopathy. 
Table 3.-Some of the Methods that have beEN USED IN THE MaNagement OF OESOPHAgeal VaRices

(r). Measures directed at the control of the varices without attempting to reduce the portal hypertension.

(a) Balloon tamponage (Patton and Johnston, 1949).

(b) Injection of sclerosing agents through an oesophagoscope (Crafoord and Frenckner, 1939).

(c) Transoesophageal ligation (Crile, I950).

(d) Oesophagogastrectomy (Phemister and Humphreys, 1947).

(e) Transverse section of the cardia (Tanner, I950).

(2). Measures intended to lower portal hypertension by decreasing the arterial inflow to the portal circulation.

(a) Splenectomy

(b) Splenic artery ligation (Everson and Cole, 1948).

(3). Measures intended to lower portal hypertension by facilitating the portal outflow.

(a) Ligature of the hepatic artery (Gray et al., 195I; Reinhoff, I95I).

(b) Omentopexy (Talma, 1898).

(c) Portasystemic anastomosis (Rosenstein, 1912; Blakemore and Lord, 1945).

evident ro years ago, it is in the clinical field that the greatest advances have occurred. There are two reasons for operating on patients with portal hypertension. The first and major one is in the treatment of haemorrhage from oesophagela varices. The second is the management of patients with hypersplenism secondary to portal hypertension. At the present time there is no evidence that ascites can be treated in man by operation, although the experimental work in animals shows promise. The majority of patients who bleed from oesophageal varices do so in a series of episodes of acute haemorrhage, each one of which may endanger the life of the patient; however, there is a smaller group in which the patient may experience recurrent small haemorrhages which will produce portasystemic encephalopathy, anaemia and ill health. The principal indications for treatment are as follows:

(I) The management of the acute haemorrhage.

(2) Prevention of recurrent haemorrhage.

(3) The treatment of hypersplenism.

It is axiomatic in medicine that when the treatment of a disease is poorly understood the number of treatments which are available and have been suggested is tremendous. Some of those recommended for the treatment of portal hypertension are shown in Table 3 .

The essential features of the treatment of acute haemorrhage are the replacement of blood loss and the arrest of bleeding by oesophageal tamponage (Saengstaken and Blakemore, 1950). For the reasons that have been previously given, in the cirrhotic group it is a matter of some urgency to pass an oesophageal tampon and arrest the bleeding to prevent both exsanguination and the onset of coma. Should a balloon, after it has been satisfactorily placed, fail to stop the bleeding, the diagnosis will be in doubt and it may then be that the patient is bleeding from a peptic ulcer. Peptic ulcers have an increased incidence in patients with cirrhosis, and sometimes account for the haemorrhage instead of the varices. The type of tampon that is used is of some importance, because although the varices are called oesophageal, in fact, they are not only oesophageal but also gastric, and haemorrhage may occur from the gastric side of the cardia rather than from the oesophagus. I would, therefore, advise the use of a tube which has on it a relatively large balloon, which can be blown up inside the stomach, so that when traction is applied it will control haemorrhage both from the stomach and the oesophagus.

The tampon must have a wide-bored tube passing beyond the balloon into the stomach, so that suction can be applied and blood continuously aspirated from the stomach. Although an oesophageal tampon can be used as a temporary measure to control the haemorrhage, it cannot be left in place indefinitely because of the danger of oesophageal ulceration. After the tube has been in place for 24 hours, the balloon is let down and traction released. Aspiration of the stomach is continued to see whether haemorrhage has ceased If it has not done so then the balloon is blown upo and traction is re-applied for a further 24-hour? period: 48 hours is probably the limit for this method of treatment, and should by the end of this time haemorrhage not be controlled, direct operation on the varices is mandatory. Probably the best operation in these circumstances is the transoesophageal ligation of the varices, either by the thoracic route (Linton and Warren, I953), or by the transabdominal route (Welch, 1956). This is only a temporary procedure and will not prevent recurrence over a period of more than about three months. It is, therefore, important to follow this operation with a definitive procedure to prevent further haemorrhage. In spite of the introduction of new techniques, the results of treatment following massive haemorrhage from the oesophageal varices in patients with cirrhosis are extremely disappointing. This has lead some authors. particularly Welch, to urge immediate operative treatment to control the haemorrhage. Although the use of the shunt operations has been advocated in the treatment of acute haemorrhage, I do not think these operations should be used in such circumstances, but should be reserved for the prevention of recurrent haemorrhage.

Numerous criticisms have been levelled at the operations of portacaval and splenorenal anas- 
tomosis. Probably the most severe of these critics has been Sir Heneage Ogilvie (1953), who wrote: 'Bleeding from the oesophageal varices raises the whole question of the surgery of portal hypertension. I know of no branch of surgery more urgently in need of debunking. The subsequent history of patients who have undergone these operations is on the average no. better than that of those who have been untreated, and when they die the new opening is usually found to be closed.' Recent statistics show that this is not so. Milnes Walker (1957) has had only two patients with recurrent haemorrhages out of 52 who have been operated on by means of a portacaval anastomosis. Out of Linton's 78 patients, followed three or more years, ro have bled since operation, in eight of these the bleeding followed a splenorenal anastomosis, which has been done on 60 patients in this series, the remainder being portacavals (Lirton, 1956). The operative mortality for portasystemic anastomosis has fallen in recent years. Child (1954) found that the operative mortality was 14 per cent. for a collected series of 362 operations. Linton (1956) in a personal series of 114 patients had an operative mortality of 12 per cent., but this has been reduced to 5 per cent. in the last 72 cases. Milnes Walker (1957) was able to publish a personal series of 55 portacaval anastornoses with an operative mortality of 5 per cent. It would seem, therefore, that two of the main criticisms against portacaval and splenorenal shunt operations have at last been settled; the operative mortality is low and the recurrent rate of haemorrhage is small, since there can be no doubt that a properly constructed anastomosis will remain patent. There is one further aspect of this problem, however, which has not, in the past, received sufficient attention; this is whether shunting of portal blood away from the liver will, in fact, affect the survival time of the patient. There is no body of evidence on which to base a conclusion. It is my opinion that the recent great improvements that have occurred in the after management of these patients ensure the success of the operations.

Any patient who has had a severe haemorrhage from oesophageal varices, which required a blood transfusion for its correction should be considered for a portacaval or splenorenal anastomosis. There must be convincing evidence that the bleeding was from the oesophageal varices. The patient's liver function must be adequate to withstand the operation. In assessing this, the criteria determined by Linton (I95I) are of great value. These are as follows: (a) no ascites should be present; (b) the serum albumen should be above $3 \mathrm{~g}$. per cent.; and (c) the serum bilirubin should be below I $\mathrm{mg}$. per cent.
Percutaneous trans-splenic portography is of the utmost value in determining the type of operation required. Details of the procedure are given by Walker, Middlemiss and Nanson (1953), and Atkinson,. Barnett, Sherlock and Steiner (1955). Complications are infrequent, but it would seem advisable to limit this investigation to those patients on whom it has been decided to operate. Du Boulay, Green and Hunt (1957) have stressed the importance of venography of both the splenic and superior mesenteric veins at operation.

In the majority of patients, both the portal and splenic veins are patent, and there is a choice of operation. In most instances a portacaval shunt should be performed rather than a splenorenal. This view is supported by Child (1955) and Walker (1957), but Linton (1956) is a protagonist for the splenorenal anastomosis, and, in his hands, the operation gives excellent results. From my own experience I would say that it is far harder to produce a satisfactory splenorenal anastomosis. It will, of course, not be possible to form a portacaval anastomosis in patients who have an extrahepatic block or who have thrombosis of the portal vein, which is secondary to cirrhosis of the liver. In these patients splenorenal operations must be carried out and in the majority it is possible to fashion a stoma which is large enough to remain patent.

The most serious post-operative complication that will arise is hepatic coma. This can be prevented by the proper selection of patients and, also, by careful pre-operative care. Three days before operation, the patient's protein intake should be reduced to $20 \mathrm{~g}$. a day, and he should be started on a course of neomycin to decrease the bacterial flora of the gut. Both of these measures are of great importance in decreasing the postoperative incidence of hepatic coma. After operation, protein should be returned to the diet gradually, starting seven days post-operatively, and working up in steps to a protein intake of $100 \mathrm{~g}$.

As stated earlier, the other main indication of the surgical treatment in patients with portal hypertension is the presence of hypersplenism. To perform a splenectomy in these patients is to do them a great disservice, although it may control the hypersplenism, it will do nothing to control the portal hypertension and they will eventually bleed again from their oesophageal varices. In many, the chance will be lost to perform a satisfactory shunt operation if the portal vein is already thrombosed. It is probable, but not yet certain, that for a case with a moderate degree of hypersplenism a portacaval shunt which relieves the portal hypertension will cause regression of the hypersplenism. The alternative is a splenectomy, 
and to follow this immediately with a satisfactory splenorenal anastomosis.

The most difficult problem of all still remains to be discussed, this is the problem of the postsplenectomy bleeder. In those in whom the portal vein is still patent, a portacaval anastomosis should be attempted, although in these circumstances it will not, with certainty, cure the patient (Walker, 1957). In some patients after splenectomy, the thrombus in the splenic vein may spread back to block the entrance of the left gastric vein into the splenic vein. In those in whom the portal vein is thrombosed the results of any form of treatment are depressing. Probably the best form of operation in these patients is a relatively radical proximal gastrectomy, excising the lower part of the oesophagus to obliterate the varices, and removing a liberal portion of the proximal part of the stomach to reduce the acid secretion (Phemister and Humphreys, 1947). An alternative to this is to carry out the operation advised by Tanner (1950), in which the stomach is transected and resutured immediately below the cardia.

The management of patients with portal hypertension is a fascinating problem and has produced a very great challenge to surgeons. I have attempted in this article to outline some of the problems that have still to be answered, and have also shown that there is now some evidence that this disease can be treated on a rational basis with surgery. I hope I have dispelled the impression that the operations of portacaval and splenorenal anastomosis are not without their value, indeed, they are the best we have to offer at the present time in the treatment of this disease.

BIBLIOGRAPHY

ALLISON, P. (195I), Thorax, 6, 325.
ATKINSON, M., BARNETT, E., SHERLOCK, S., and STEINER, R. E. (1955), Quart. F. Med., n.s., 24, 77.

BLAKEMORE, A. H., and LORD, J. W. (1945), Ann. Surg., I22, 476.

CHILD, C. G. (1954), 'The Hepatic Circulation and Portal Hypertension,' W. B. Saunders Co., Philadelphia.

CHILD, C. G. (1955), New Engl. F. Med., 252, 837.

CHILD, C. G. HOLSWADE, G. R. McCLURE, R. D., GORE, A. L., and O'NEILL, E. A. (1952), Surg. Gynec. Obstet., 94, 3I

CHILD, C. G., MILNES, R. F., HOLSWADE, G. R., and GORE, A. L. (1950), Ann. Surg., 132, 475.

CRAFOORD, C., and FRECKNER, P. (1939), Acta oto-laryng., 27, 422.

CRILE, G. (1950), Arch. Surg. (Chicago), 61, 654.

Du BOULAY, G. H., GREEN, B., and HUNT, A. H. (1957), Brit. med. $\mathcal{F} ., \mathrm{i}, \mathrm{I} 89$.

EVERSON, T. C., and COLE, W. H. (1948), Arch. Surg. (Chicago), $56,153$.

GRAY, H K MANN, F, C., BOLLMAN, J L and GRINDLAY, H. J. (195I), Ann. roy. Coll. Surg. Engl., 8, 354 LINTON, R. R. (I95I), Ann. Surg., 134, 433.

LINTON, R. R. (1956) 'Portal Hypertension in Disease of the Liver,' Pitman, London, Edit. Schiff, $L$.

LINTON, R. R., and WARREN, R. (1953), Surgery, 33, 243.

MADDEN, J. L., LORE, J. M., GEROLD, F. P., and RAVID, J. M. (1954), Surg. Gynec. Obstet., 99, 385.

McDERMOTT, W. V., RIDDELL, A. G., and ADAMS, R. D. (1954), Ann. Surg., 140, 539.

MCDERMOTT, W. V., WAREHAM, J., and RIDDELL, A. G. (1956), Ibid., 144, 318.

OGILVIE, H. (1953), Surgery, 34, 768.

PATTON, T. B., and JOHNSTON, C. G. (1949), Arch. Surg. (Chicago), 59, 502.

PHEMISTER, D. B., and HUMPHREYS, E. M. (1947), Ann. Surg., 126, 397.

RAVDIN, I. S. (1957), Ann. roy. Coll. Surg. Engl., 20, 7 I.

RIDDELL, A. G. (1955), Postgrad. med. F., 31, 389.

RIDDELL, A. G. (1955), Ann. roy. Coll. Surg. Engl., 17, 319.

RIENHOFF, W. F. (195I), fohns Hopk. Hosp. Bull., 88, 368.

ROSENSTEIN, P. (1912), Arch. klin. Chir., 98, 1082.

SAENGSTAKEN, R. W., BLAKEMORE, A. H. (1950), Ann Surg., 131, 781.

TALMA, S. (1898), Berlin klin. Wschr., 35, 833.

TANNER, N. C. (1950), Proc. roy. Soc. Med., 43, 147.

TAYLOR, F. W. (1954), Ann. Surg., 140, 652.

WAGENKNECHT, T. W., NOBLE, J. F., and BARONOFSKY, I. D. (1953), Surgery, 33, 869 .

WALKER, R. M. (1957), Lancet, i, 57.

WALKER, R. M., MIDDLEMISS, J. H., and NANSON, E. M. (1953), Brit. $\mathscr{F}$. Surg., 40, 392.

WELCH, C. S. (1956), New Engl. F. Med., 255, 677.

WHIPPLE, A. O. (1945), Ann. Surg., 122, 449.

\section{NOTICE OF SPECIAL - INTEREST TO SUBSCRIBERS:}

'WHY NOT HAVE YOUR COPIES OF THIS
JOURNAL BOUND INTO YEARLY VOLUMES?'

You can have your twelve monthly issues fully bound in dark green pin head cloth. lettered in gilt on spine with name of Journal, Volume Number and year, complete with index at front, for $22 \mathrm{~s}$. 6d. post free. A limited number of out of print journals are available to bind into volumes and make your library complete. Price on application giving details of issues required to complete back volumes.

THE
WHY NOT

HAVE YOUR

JOURNALS BOUND? 